\title{
Silver as acrolein hydrogenation catalyst: Intricate effects of catalyst nature and reactant partial pressures
}

\author{
M. Bron ${ }^{1 \S}$, D. Teschner ${ }^{2}$, A. Knop-Gericke ${ }^{2}$, F.C. Jentoft ${ }^{2}$, J. Kröhnert ${ }^{2}$, J. Hohmeyer ${ }^{1,2}$, C. Volckmar ${ }^{1}$, B. \\ Steinhauer ${ }^{2}$, R. Schlögl ${ }^{2}$, P. Claus ${ }^{1 *}$ \\ ${ }^{1}$ Ernst-Berl-Institute of Technical and Macromolecular Chemistry, Darmstadt University of Technology, \\ Petersenstr. 20, D-64287 Darmstadt, Germany \\ ${ }^{2}$ Department of Inorganic Chemistry, Fritz-Haber-Institute of the MPG, Faradayweg 4-6, 14195 Berlin, Germany \\ * Corresponding author: e-mail claus@ct.chemie.tu-darmstadt.de, Tel.: ++49-6151-165369, Fax: ++49-6151-164788 \\ ${ }^{\S}$ present address: Ruhr-University Bochum, Analytische Chemie - Elektroanalytik und Sensorik, Nachwuchsgruppe \\ Brennstoffzellen, Universitätsstrasse 150, Gebäude NC 04/123, D-44801 Bochum, Germany
}

\begin{abstract}
The hydrogenation of acrolein over pure and supported silver has been investigated with a focus on the influence of catalyst structure and reaction pressure (mbar to 20 bar range) on activity and selectivity. An onset of formation of allyl alcohol beyond 100 mbar reaction pressure (at 250 ${ }^{\circ} \mathrm{C}$ ) is ascribed to a change in adsorption geometry upon increasing coverage. Smaller silver particles (in the nanometer range), the proximity of reducible oxide component as well as high pressure lead to enhanced allyl alcohol formation; the selectivity to the other main product propionaldehyde is reduced. The silver dispersion changed depending on the reaction pressure. Moreover, the presence of oxygen, most likely as subsurface oxygen, and the presence of defects are of paramount importance for the catalytic behaviour. The considerable changes of the silver catalysts under reaction conditions and the pressure dependence call for in situ-measurements to establish true structure - activity/selectivity relationships for this system.
\end{abstract}

\section{Introduction}

The catalytic hydrogenation of $\alpha, \beta$-unsaturated aldehydes is of interest both from a fundamental as well as an applied point of view. ${ }^{1,2,3} \alpha, \beta$-Unsaturated aldehydes can be hydrogenated at the $\mathrm{C}=\mathrm{C}$-double bond leading to the saturated aldehyde, or at the $\mathrm{C}=\mathrm{O}$-bond leading to the unsaturated alcohol, which is the industrially relevant product (see Fig. 1). Unfortunately, the former reaction is thermodynamically favoured. It is often proposed that the adsorption geometry of the unsaturated aldehyde is determining selectivity ${ }^{4,5,6,7}$, however, this view has been recently challenged by theoretical investigations. Based on density functional theory (DFT) calculations, Loffreda and Sautet concluded that for acrolein hydrogenation on $\operatorname{Pt}(111)$, the barriers for desorption of the different products govern the selectivity $^{8}$; similar results have been obtained by Khanra et al. for acrolein hydrogenation on $\operatorname{Ag}(111)^{9}$ using BOC-MP calculations.
When employing typical hydrogenation catalysts like Pt supported on non-reducible oxides, the selectivity to the unsaturated alcohol is poor when lower unsaturated aldehydes are used as educts ${ }^{1}$. However, various attempts have been reported to enhance the selectivity to the unsaturated alcohol, e.g. a second metal may be added. ${ }^{1,2,3}$ Three ways of action of the second metal have been proposed, which are not always distinguishable. One possibility is alloy formation, another the deposition of oxidic species of the second metal on the active metal. Both scenarios result in an enhanced selectivity to the allylic alcohols via the formation of special active sites able to activate and hydrogenate the $\mathrm{C}=\mathrm{O}$-double bond. In the third case the second metal acts as a poison and leads to a decrease in activity and sometimes also selectivity.

Another approach to improve the selectivity to unsaturated alcohols is the use of partially reducible supports like $\mathrm{TiO}_{2}$, and reduction of the catalyst at $500{ }^{\circ} \mathrm{C}$ or higher temperature $^{10,11}$ Such treatment leads to the so-called 
SMSI-state (SMSI $=$ strong metal-support interaction) and at the same time to enhanced selectivity to allylic alcohols in the hydrogenation of unsaturated aldehydes. The improved selectivity in this case is attributed to the decoration of the active metal with partially reduced support material like $\mathrm{TiO}_{2-\mathrm{x}}$. These oxidic patches provide Lewis acid sites, which are claimed to coordinate and activate the carbonyl group via the oxygen. In this way, selectivities of $>50 \%$ have been obtained for crotonaldehyde hydrogenation over $\mathrm{Pt} / \mathrm{TiO}_{2}{ }^{12}$

The selectivity also depends on the substrate to be hydrogenated. Bulky substituents at the $\mathrm{C}=\mathrm{C}$ group hinder the coordination to the surface and thus $\mathrm{C}=\mathrm{O}$ hydrogenation becomes more likely. ${ }^{4,5,13}$ Therefore, the simplest $\alpha, \beta$ unsaturated aldehyde, acrolein, with no substituents at the $\mathrm{C}=\mathrm{C}$ bond is the most difficult to be hydrogenated with high selectivities to allylic alcohol. The only monometallic catalysts that are known to produce allyl alcohol with selectivities near $50 \%$ from acrolein are silver ${ }^{14-17}$ and gold ${ }^{18-21}$. Recently, we have shown that silver, when supported on $\mathrm{ZnO}$, exhibits a selectivity to allyl alcohol of $55 \%$, ${ }^{22}$ even further enhancement (up to $70 \%$ ) can be obtained with supported AgIn catalysts. ${ }^{23,24}$

At first sight it is surprising that silver (and gold) can be used for hydrogenation reactions in heterogeneous catalysis at all. From theoretical as well as experimental studies it is well-known that hydrogen interacts only very weakly with extended silver surfaces (single crystals, polycrystalline surfaces), and no dissociative chemisorption should occur at low temperature. ${ }^{25-32}$ The completely filled d-band of silver as well as the position of the d-band center relative to the Fermi level have been claimed to be the reason for the lack of reactivity towards $\mathrm{H}_{2} \cdot{ }^{33,34}$ The solubility of $\mathrm{H}_{2}$ in $\mathrm{Ag}$ is extremely small below $400{ }^{\circ} \mathrm{C}$; at higher temperatures the absorbed amount is proportional to $\operatorname{sqr}(\mathrm{p})$ in the range 65-1065 mbar, indicating dissociation of $\mathrm{H}_{2}{ }^{35}$ Moreover, as early as 1954 Boudart and colleagues ${ }^{36}$ were able to demonstrate that at higher temperatures $\left(\mathrm{T}>70{ }^{\circ} \mathrm{C}\right.$, depending on sample) indeed H-D isotopic exchange occurred over silver foil or granular silver. Thermal promotion of d-electrons into s-orbitals has been made responsible for this process. Very recent results of Rösch et al. ${ }^{37}$ show that hydrogen activation on $\operatorname{Ag}(111)$ should be strongly facilitated in presence of an added row of oxygen or subsurface $\mathrm{O}$.

In principle, metal catalysts are very suitable for model studies using surface science techniques. However, typical operating pressures for hydrogenation are 10-20 bar, raising the question as to whether the reaction proceeds in the same way at lower pressures or, vice versa, whether results obtained under near-vacuum conditions can be extrapolated ("pressure gap"). Furthermore, the support material can play a role, and hence pure silver may not be a representative model ("materials gap"). In the present contribution, we address these concerns and discuss the results in light of the latest theoretical and experimental findings of other groups. Specifically, the influence of pressure was studied over a wide range, and different materials were

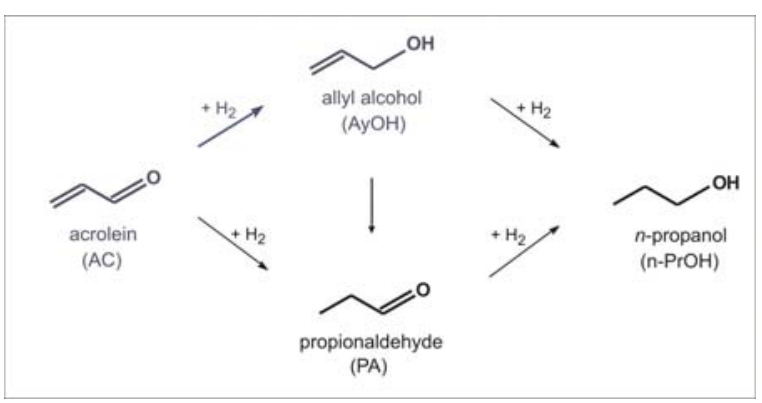

Figure 1: Reaction scheme for acrolein hydrogenation

used such as single- and poly-crystalline silver, Ag deposited on the non-reducible supports $\mathrm{SiO}_{2}$ or $\mathrm{Al}_{2} \mathrm{O}_{3}, \mathrm{Ag} / \mathrm{ZnO}$, and $\mathrm{Ag} / \mathrm{SiO}_{2}$ with indium added. Acrolein hydrogenation over silver catalysts can be considered as a parallel reaction (hydrogenation of either double bond, Fig. 1); the hydrogenation of the respective second double bond is largely suppressed, at least at conversions below $60 \%{ }^{16}$ used through this paper. Thus influence of pressure and material not only on activity, but also on selectivity can be evaluated. A further aim was to elucidate how hydrogen is activated on silver catalysts.

In the course of our studies, the reaction conditions were found to affect the state of the catalyst, i.e. size, structure and degree of reduction of the silver particles changed, with a strong influence of the support. The task of relating the performance to individual reaction parameters or catalyst properties became thus very complex.

The paper is organised as follows: First, the various factors influencing selectivity (pressure, silver structure, support material and degree of reduction) are discussed separately, followed by a chapter on hydrogen activation on silver catalysts. Finally, there will be a discussion in which the interplay of the various factors as well as the importance of subsurface oxygen or the proximity of oxide patches and defect sites is highlighted.

\section{Influence of pressure}

The influence of the reaction pressure on the selectivity to allyl alcohol over $\mathrm{Ag} / \mathrm{SiO}_{2}$ catalysts has been studied in the pressure range from 2 mbar to 20 bar. $^{17}$ The results of these investigations are summarised in Fig. 2 (see figure captions for conditions and ref. ${ }^{17}$ for more experimental details). As can be seen, a minimum pressure of ca. 100 mbar is necessary for allyl alcohol (AyOH) formation. Below this pressure, the only hydrogenation product is propanal (PA). It should be mentioned that the selectivity values (with the exception of the low-pressure value at 7.5 mbar) of Fig. 2 have been obtained at conversions between ca. 15 to $35 \%$. The conversion in this range has only very little influence on selectivity in the case of acrolein hydrogenation over silver. This has been evaluated in more detail for two $\mathrm{Ag} / \mathrm{SiO}_{2}$-catalysts. ${ }^{16}$ In the same study, we have shown that the dependence of selectivity on reaction pressure results from the dependence of both the partial pres 

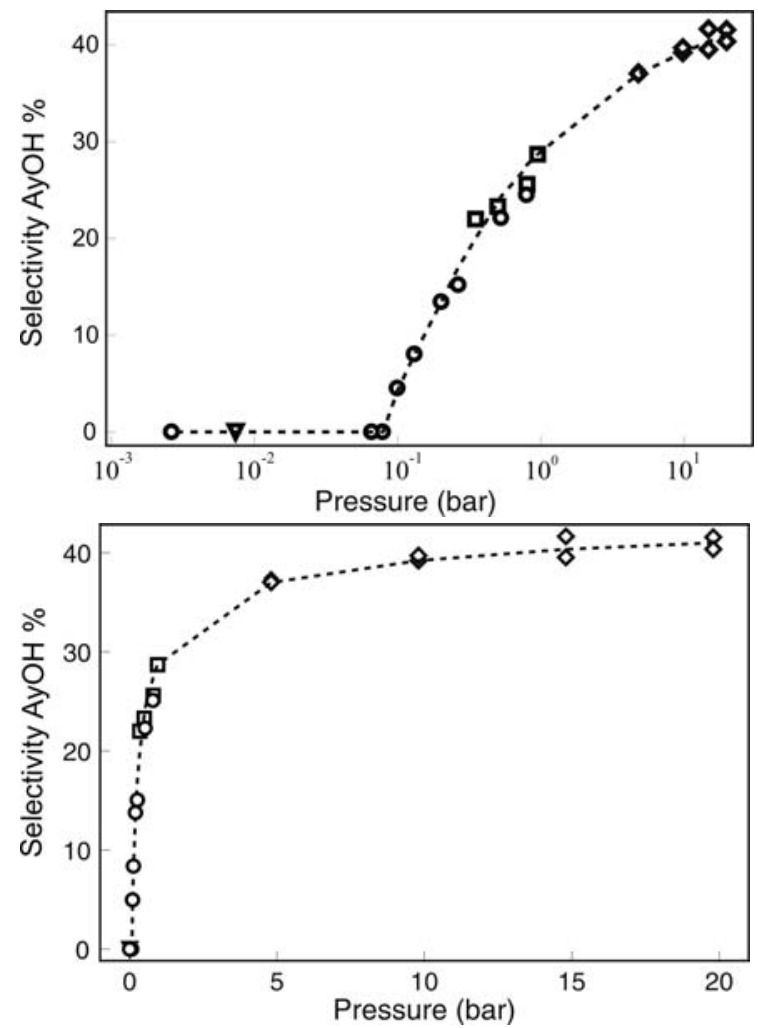

Figure 2: Dependence of the selectivity to allyl alcohol on the reaction pressure over an $\mathrm{Ag} / \mathrm{SiO}_{2}$ catalyst, a) logarithmic and b) linear pressure scale. Silver loading was $7.5 \%$, reaction temperature $250{ }^{\circ} \mathrm{C}$ and $\mathrm{H}_{2}$ /Acrolein ratio $20: 1$. Different symbols represent experiments in different setups. (Figure 2a is reprinted from Ref. 17 with permission from Elsevier.)

sure of acrolein and of hydrogen. Also the overall reaction rate depends on the partial pressures of both reactants. Assuming a simple power law

$$
\mathrm{r}=\mathrm{k}^{*} \mathrm{p}_{\mathrm{H} 2}{ }^{\mathrm{m}} * \mathrm{p}_{\mathrm{AC}}{ }^{\mathrm{n}}
$$

with

$$
\mathrm{k}(\mathrm{T})=\mathrm{k}_{0} \mathrm{e}^{-\mathrm{Ea} / \mathrm{RT}}
$$

one can deduce kinetic parameters for the overall reaction rate (acrolein consumption) as well as for individual hydrogenation routes. These are compiled for an $\mathrm{Ag} / \mathrm{SiO}_{2-}$ catalyst $^{16}$ with a metal loading of $8.1 \%$ in Table 1 . Note that the values in Table 1 have been obtained at two different total pressures. The partial pressure of one reactant has been varied and the partial pressure of the other has been kept constant by adding the respective amount of inert gas as balance, using a continuous gas flow reactor. Acrolein partial pressures were from $0.12 \ldots 0.47$ bar ( 5 bar total pressure) or $0.36 \ldots 1.4$ bar (15 bar total pressure), and for hydrogen from $1.58 \ldots 4.74$ bar (5 bar total pressure) or $4.74 \ldots 14.21$ bar (15 bar total pressure). Conversion was always $<20 \%$.

Positive, partial reaction orders are obtained for both acrolein and hydrogen. This indicates that the active sur
Table 1: Reaction orders for the hydrogenation of acrolein over $8.1 \% \mathrm{Ag} / \mathrm{SiO}_{2}$ at $250{ }^{\circ} \mathrm{C}$

\begin{tabular}{|l|l|l|l|l|}
\hline & $\begin{array}{l}\mathrm{m} \\
(5 \text { bar })\end{array}$ & $\begin{array}{l}\mathrm{m} \\
(15 \text { bar })\end{array}$ & $\begin{array}{l}\mathrm{n} \\
(5 \text { bar })\end{array}$ & $(15$ bar $)$ \\
\hline $\begin{array}{l}\text { Acrolein } \\
\text { consumption }\end{array}$ & 0.63 & 0.81 & 0.71 & 0.53 \\
\hline $\begin{array}{l}\text { Propanal } \\
\text { formation }\end{array}$ & 0.61 & 0.76 & 0.66 & 0.53 \\
\hline $\begin{array}{l}\text { Allyl alcohol } \\
\text { formation }\end{array}$ & 0.67 & 0.90 & 0.81 & 0.54 \\
\hline
\end{tabular}

face is not saturated with either reactant, and likely both influence the rate determining step. Higher reaction orders for $\mathrm{AyOH}$ formation compared to $\mathrm{PA}$ formation are in agreement with higher selectivity to $\mathrm{AyOH}$ at higher partial pressure of both reactants. Additionally, it can be seen that the reaction orders for hydrogen are higher at higher pressures, whereas those for acrolein are lower. This indicates that at higher pressure the surface becomes more and more saturated with acrolein, leading to a weaker influence of acrolein partial pressure. At 5 bar reaction pressure, a still moderate coverage of the silver nanoparticles with acrolein $\left(\theta=0.06-0.14 \mathrm{~N}_{\mathrm{AC}} / \mathrm{N}_{\mathrm{Ag} \text {-surface }}\right)$ has been calculated from EXAFS analysis at the Ag K-edge, as detailed in ref. ${ }^{38}$. Note that full coverage on a (111) surface can be reached at $0.25 \mathrm{~N}_{\mathrm{AC}} / \mathrm{N}_{\mathrm{Ag} \text {-surface }}$. On the other hand, acrolein interacts strongly with the support giving rise to high acrolein coverage on the oxide support, as indicated by IR experiments. ${ }^{16}$ Since positive reaction orders are obtained for both reactants, it is obvious that the overall activity also increases with reaction pressure.

In order to gain insight into the chemisorption of acrolein on silver during acrolein hydrogenation, in situ XAS measurements at the $\mathrm{C} \mathrm{K}$-edge have been carried out at 7.5 mbar. ${ }^{39}$ Primarily single crystals can allow angular dependent experiments, in which, as a consequence of the dipole selection rule, transitions of molecule orbitals aligned in a particular way to the surface will contribute more or less to the spectrum depending on the angle of the incident electric field vector with respect to the surface. From the experiments described in ref. ${ }^{39}$ it was concluded that during hydrogenation below the threshold pressure, i.e. where only the $\mathrm{C}=\mathrm{C}$ bond is hydrogenated, a propionaldehyde-like species exists on the surface. It is either a halfhydrogenated surface species or an adsorbed propionaldehyde, whose desorption is characterized by the highest energy barrier in the hydrogenation route. The similarities of X-ray absorption spectra of single crystals and of $\mathrm{Ag} / \mathrm{SiO}_{2}$ catalysts indicate that the same intermediate is likely formed on supported catalysts as well. Recent attempts to monitor the dependence of adsorption geometry of acrolein on $\mathrm{Ag} / \mathrm{SiO}_{2}$ as a function of reaction pressure using IR spectroscopy failed, since the interaction of acrolein with the silica support was too strong and masked the interaction of acrolein with silver ${ }^{40,41}$ Assuming that the 
Table 2: Selectivity to allyl alcohol obtained over various silver catalysts at two different pressures and $250{ }^{\circ} \mathrm{C}$. Data taken from Fig. 5 and 6 of ref. ${ }^{17}$

\begin{tabular}{|l|l|l|l|}
\hline Catalyst & Structural features (method) & \multicolumn{2}{|l|}{ Selectivity to allyl alcohol (\%) } \\
\hline $7.5 \mathrm{Ag} / \mathrm{SiO}_{2}-\mathrm{IW}$ & Average particle size $2.5 \mathrm{~nm}(\mathrm{TEM})$ & $41.6(20 \mathrm{bar})$ & $28.7(950 \mathrm{mbar})$ \\
\hline $8.1 \mathrm{Ag} / \mathrm{SiO}_{2}$ - $\mathrm{DP}(\mathrm{NaOH})$ & Average particle size $14.2 \mathrm{~nm}(\mathrm{TEM})$ & $37.6(20 \mathrm{bar})$ & \\
\hline $\mathrm{Ag} / \mathrm{SiO}_{2}$-sputtered & Particle size ca. $20 \ldots 200 \mathrm{~nm}(\mathrm{TEM})$ & $22.7(20 \mathrm{bar})$ & $12.1(980 \mathrm{mbar})$ \\
\hline $\mathrm{Ag} / \mathrm{Al}$-sputtered & (film thickness: $100 \mathrm{~nm})$ & & $9(983 \mathrm{mbar})$ \\
\hline $\begin{array}{l}\mathrm{Ag} / \mathrm{Al} \text {-electrochemical } \\
\text { deposited }\end{array}$ & (film thickness: $100 \mu \mathrm{m})$ & & $1 \pm 1(980 \mathrm{mbar})$ \\
\hline
\end{tabular}

adsorption geometry governs the selectivity, at least two geometries for acrolein on the surface should exist, one leading to allyl alcohol formation, and one to propionaldehyde formation. In fact, we were recently able to show with high-pressure EXAFS (performed at 5 bar at the Ag K-edge under reaction conditions in a flow cell similar to our lab reactors, as described in ${ }^{38}$ ) that the metal-adsorbate interaction is different in $\mathrm{Ag} / \mathrm{SiO}_{2}$ and $\mathrm{AgIn} / \mathrm{SiO}_{2}$-catalyst during acrolein hydrogenation: the atomic distances between metal and adsorbate are smaller for $\mathrm{AgIn} / \mathrm{SiO}_{2}$ catalysts than for $\mathrm{Ag} / \mathrm{SiO}_{2}$ catalysts, which is likely due to differences in adsorption geometries. These samples exhibit different selectivity-patterns in acrolein hydrogenation ${ }^{38}$ (see Table 4). However, the exact adsorption geometry could not be determined. Since in situ XAS at the $\mathrm{C} K$-edge has shown that at low pressures $(7.5 \mathrm{mbar})$ a flat adsorption geometry exists (see above and ${ }^{39}$ ), which leads to PA, it is likely, that at higher pressure (i.e., higher surface coverage) lateral interactions may lead to a change in adsorption geometry to a more upright, less surface area consuming geometry.

However, the influence of reaction pressure on the selectivity is clearly more complex. We observed that the pressure not only has a profound influence on the selectivity in acrolein hydrogenation, but also on the structural modification of the silver nanoparticles during reaction, as discussed below.

\section{Influence of material (structural features of silver, support)}

The influence of nanostructure (i.e. particle size or film thickness) on the activity and selectivity in acrolein hydrogenation over $\mathrm{Ag} / \mathrm{SiO}_{2}$ catalysts and silver films has been studied by varying the particle size of the supported nanoparticles or the film thickness. These experiments, which have been described in detail $\mathrm{in}^{17}$, will be summarized in the following. In Table 2, the selectivity to allyl alcohol is depicted for various Ag catalysts in the high pressure region (20 bar) and for ca. 1 bar. For the supported nanoparticles, the selectivity to allyl alcohol increases with decreasing particle size up to a value of $42 \%$ (particle sizes have been obtained from TEM analysis ${ }^{17}$ ). Some caution is however called for, as the respective catalysts have been prepared with different methods. An additional influence on the catalytic properties can thus not be excluded, but only in this way the preparation of a very broad range of particle sizes was possible. The selectivity towards allyl alcohol over the bulk materials is significantly smaller than for the supported nanoparticles and is below $10 \%$ at 950 mbar. Allyl alcohol formation therefore seems to be linked to active sites most abundant on small nanoparticles, i.e. to low coordination sites like steps and kinks. Recent aberration corrected high-resolution TEM images taken on a $7.5 \mathrm{Ag} / \mathrm{SiO}_{2}$-IW catalyst (Fig. 3) clearly validate the presence of atomic steps on the surface of silver nanoparticles. Note that, although the average particle size of such prepared catalysts is rather small (see table 2), there are also larger particles found in TEM analysis ${ }^{16}$.

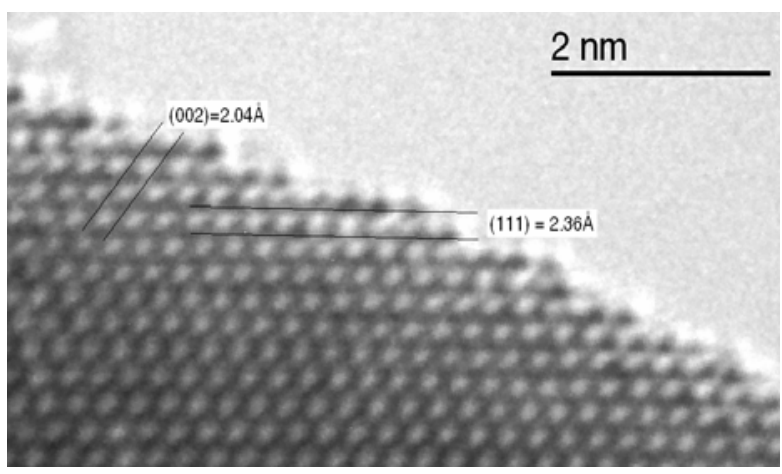

Figure 3: Aberration corrected high-resolution TEM image of a silver nanoparticle in $\mathrm{Ag} / \mathrm{SiO}_{2}$ catalyst showing atomic steps at the surface.

In order to compare the activities in terms of TOF (turn over frequency), the metal surface areas of the catalysts $7.5 \mathrm{Ag} / \mathrm{SiO}_{2}$-IW (average particle size $2.5 \mathrm{~nm}$ ) and $8.1 \mathrm{Ag} / \mathrm{SiO}_{2}$-DP (average particle size $\left.14.2 \mathrm{~nm}\right)^{16}$ have been estimated assuming ideal cuboctahedral crystal shape. ${ }^{42,43}$ The results for the two most thoroughly investigated catalysts are displayed in Table 3, where the TOF in number of 
Table 3: Activity of two $\mathrm{Ag} / \mathrm{SiO}_{2}$ catalysts in acrolein hydrogenation at various reaction pressures $\left(\mathrm{AC}: \mathrm{H}_{2}=1: 20\right)$ and $250^{\circ} \mathrm{C}$

\begin{tabular}{|c|c|c|}
\hline $\begin{array}{c}\text { Reaction } \\
\text { pressure }\end{array}$ & $\begin{array}{c}7.5 \mathrm{Ag} / \mathrm{SiO}_{2}-\mathrm{IW} \\
\mathrm{TOF}\left(\mathrm{s}^{-1} * 10^{-2}\right)\end{array}$ & $\begin{array}{c}8.1 \mathrm{Ag} / \mathrm{SiO}_{2}-\mathrm{DP} \\
\mathrm{TOF}\left(\mathrm{s}^{-1} * 10^{-2}\right)\end{array}$ \\
\hline $5 \mathrm{bar}$ & 2.0 & 2.0 \\
\hline $10 \mathrm{bar}$ & 5.0 & 4.1 \\
\hline $15 \mathrm{bar}$ & 8.1 & 6.0 \\
\hline $20 \mathrm{bar}$ & 9.1 & 7.3 \\
\hline
\end{tabular}

converted acrolein per second and per surface silver atom is displayed for various pressures.

Allyl alcohol formation was connected to special surface sites that are more abundant on small nanoparticles, i.e., the reaction is structure sensitive regarding selectivity. Regarding activity though, the reaction seems to be rather structure insensitive, at least for particle sizes in the investigated range. The TOF values in Table 3 have been calculated using particle sizes measured before the catalytic experiment, which was found to be justified by measurement of the size after reaction as discussed below. Similar structure insensitivity regarding activity has also been observed for $\mathrm{Ag} / \mathrm{Al}_{2} \mathrm{O}_{3}$ in the range of 11 to $17 \mathrm{~nm}^{22}$ (i.e., particle sizes less typical for size effects) and for crotonaldehyde hydrogenation over $\mathrm{Ag} / \mathrm{SiO}_{2}$ from 3.7 to $6.3 \mathrm{~nm}^{44}$ For $\mathrm{Ag} / \mathrm{TiO}_{2}$ though, the particle size seemed to have an influence on activity in the range $1.4-2.8 \mathrm{~nm} .{ }^{44}$ However, $\mathrm{Ag}$ nanoparticles were found decorated with $\mathrm{TiO}_{\mathrm{x}}{ }^{15}$ hence the observed effect could not solely be reduced to particle size.

Beyond the above-established selectivity(activity)structure correlation the situation becomes more complex under certain conditions. During our investigations, significant sintering of silver nanoparticles occurred, when they were used in mbar reaction conditions; the effect was even more pronounced when TPD experiments (i.e. at UHV condition) were carried out. SEM images (Fig. 4) reveal silver particles even larger than $1 \mu \mathrm{m}$ after use of the sample in catalysis (several reaction cycles at $250{ }^{\circ} \mathrm{C}$ in the mbar range) and subsequent heat treatment during TDS experiments to a maximum of $300^{\circ} \mathrm{C}$ in vacuum. Sintering in similar extent has not been observed under high pressure conditions (5-20 bar, i.e. the typical region of industrial hydrogenation catalysis) even after long term use. To obtain more insight into the structure of the silver catalyst and possible changes under reaction conditions, in situ EXAFS measurements have been performed at the $\mathrm{Ag} K$-edge at a pressure of 5 bar using a $5 \% \mathrm{Ag} / \mathrm{SiO}_{2}$ catalyst, as discussed in ref. ${ }^{38}$. These investigations have shown that under reaction condition, the silver nanoparticles exhibit bulk silver fcc structure. The particle size found under reaction conditions was only slightly larger than before the experiment. By TEM analysis of $\mathrm{Ag} / \mathrm{SiO}_{2}$ catalyst before and after catalysis at 10 bar, sintering from 7.4 to $11.4 \mathrm{~nm}$ average particle size has been observed. ${ }^{45}$ In such high pressure catalytic experiments, there was only a slight decrease in activity during the first two hours accompanied by a small decrease in AyOH selectivity, until steady state was obtained. Hence, at high pressure sintering seems to be less pronounced. Because the particle size changes under high pressure conditions do not exceed a few $\mathrm{nm}$, our correlation of selectivity with the initial $\mathrm{Ag}$ particle size in $\mathrm{Ag} / \mathrm{SiO}_{2}$ catalysts remains valid (Table 2 ).

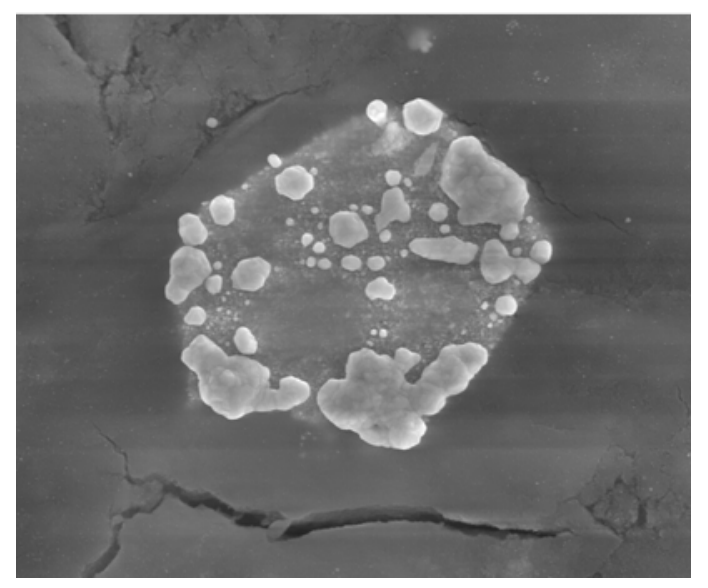

Figure 4: $\mathrm{SEM}$ image of an $\mathrm{Ag} / \mathrm{SiO}_{2}$ catalyst after use in catalytic and TPD experiments (UHV environment) at 250 ${ }^{\circ} \mathrm{C}$.

As opposed to the sintering phenomena on the silica support, the reverse effect, i.e., a redispersion of the silver has been observed for $\mathrm{Ag} / \mathrm{ZnO}$ after high pressure hydrogenation. In Fig. 5, the silver content according to XPS Ag3d signal intensities is displayed, which were obtained during an in situ-study on $\mathrm{Ag} / \mathrm{ZnO}$. The left two bars have been obtained with the catalyst as prepared and reduced (grey bar) and after use in high pressure (20 bar) catalysis. ${ }^{1}$ The higher signal intensity of the used catalyst in Fig. 5 can be understood considering that the sampling depth of XPS is limited. Only the outer part of a large particle will contribute to the spectrum, while for smaller particles, a relatively larger fraction is probed, leading to higher signal intensities. On the other hand, when using the catalyst in low pressure experiments (1 mbar), the XPS signal decreases (right two bars in Fig. 5), indicating sintering of the silver particles, as observed already for silica supported samples. Therefore the influence of structural parameters on the reaction selectivity is sometimes complicated by the effect of the respective pressure on the particle morphology.

Use of different support materials introduces a further parameter influencing the hydrogenation performance. The data in Table 4 clearly indicates that the selectivity depends significantly on the nature of the support or further

\footnotetext{
${ }^{1}$ After reaction at $20 \mathrm{bar}$, the samples have been allowed to cool down in flowing hydrogen at 20 bar, however, after reaching room temperature the reactor has been opened in air to demount the samples. After a short storage time in the order of days, the samples have been investigated by XPS. Most likely the short storage is not responsible for the observed particle size change described in the following.
} 
Table 4: Overview of AyOH selectivity of supported Ag catalysts prepared by incipient-wetness in gas-phase acrolein hydrogenation

\begin{tabular}{|c|c|c|c|}
\hline Catalyst & Mean particle size & Pressure (bar) & Max. selectivity (\%) \\
\hline $7.5 \% \mathrm{Ag} / \mathrm{SiO}_{2}$ & $2.5 \mathrm{~nm}$ & 10 & 39 \\
\hline $5 \% \mathrm{Ag} / \mathrm{Al}_{2} \mathrm{O}_{3}$ & $11 \mathrm{~nm}$ & 10 & 42 \\
\hline $5 \% \mathrm{Ag} / \mathrm{ZnO}$ & broad distribution & 10 & 50 \\
\hline $9 \% \mathrm{Ag} 0.75 \% \mathrm{In} / \mathrm{SiO}_{2}$ & $5 \mathrm{~nm}$ & 20 & 61 \\
\hline
\end{tabular}

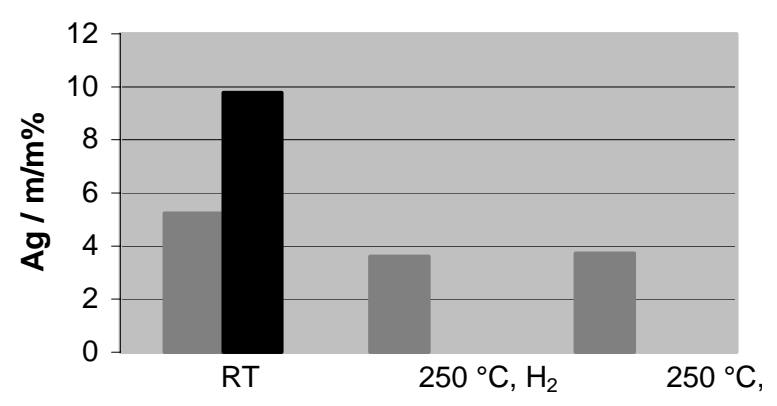

Figure 5: Silver content according to the XPS Ag 3d signal of an $\mathrm{Ag} / \mathrm{ZnO}$ catalyst under various conditions. Black bar: after use in catalysis at 20 bar; grey bars: as prepared and reduced (at $\mathrm{RT}$, at $250{ }^{\circ} \mathrm{C}$ in $1 \mathrm{mbar}_{2}$ and in 1 mbar reaction mixture)

additives. Note that all catalysts in Table 4 have been prepared using the same preparation method and precursor, and all experiments have been carried out under similar reaction conditions. ${ }^{17}$ First of all, the dispersion of Ag was found to vary with the support, therefore correlations are not easily established. For example, particles on $\mathrm{ZnO}$ showed a much broader particle size distribution in comparison to those supported on $\mathrm{SiO}_{2}$, and hence the good selectivity (but lower activity) of $\mathrm{Ag} / \mathrm{ZnO}$ is likely ascribed to the combination of less-active large particles and few active small particles in close interaction with the support. $\mathrm{Ag} / \mathrm{Al}_{2} \mathrm{O}_{3}$ catalysts exhibit slightly improved $\mathrm{AyOH}$ selectivity with TOFs similar to that of $\mathrm{Ag} / \mathrm{SiO}_{2}$. However, the large variations in maximum selectivity that could be obtained indicate, that not only the particle size, but also the nature of the support influences selectivity. Note that $\mathrm{Al}_{2} \mathrm{O}_{3}$ as supports leads to higher selectivity to allyl alcohol even though larger Ag particles are present. Additionally, preliminary results on acrolein hydrogenation at 10 bar over $\mathrm{Ag} / \mathrm{SiO}_{2} / \mathrm{Al}_{2} \mathrm{O}_{3}$ catalysts with varying $\mathrm{SiO}_{2}$-to- $-\mathrm{Al}_{2} \mathrm{O}_{3}$ ratio, prepared with the same method and having similar particle size, indicate that the support nature in fact influences the selectivity to allyl alcohol. This may be related to different acidities or to special sites (e.g., stabilization of defects) at the metal-support interface.

The best selectivity was achieved when indium was added during preparation of the impregnated sample. ${ }^{23,24}$ In-situ EXAFS experiments under hydrogenation conditions suggest that the excellent performance is related to the presence of oxidized indium. ${ }^{38}$ Indium ions can act as Lewis acid sites, which might assist in the reaction. Alter- natively, reducible oxides (indium, zinc) in principle allow for a transfer of oxygen to the $\mathrm{Ag}$ phase, creating electropositive silver sites. The effect of oxygen on the catalyst is thus of interest.

\section{Influence of oxygen pre-treatment}

Beside the effect of the above discussed parameters, pre-treatment of the catalysts with oxygen has a profound influence on both activity and selectivity. Typically, air treatment increased the activity of catalysts two to three fold $^{45}$. In Fig 6, the selectivity to allyl alcohol in acrolein hydrogenation is displayed for different pre-treatments applied to a $\mathrm{Ag} / \mathrm{ZnO}$ catalyst at a reaction pressure of 800 mbar as investigated in a closed-loop batch circulation setup. Deactivation of the samples, likely resulting from sintering of the silver nanoparticles in low pressure or in vacuum at reaction temperature (evacuation between catalytic runs), was accompanied by a decrease in allyl alcohol selectivity from 29 to $10 \%$. When the catalyst was treated in flowing air at $40 \mathrm{mbar}$ for $2 \mathrm{~min}$. after deactivation and reused in the gas phase hydrogenation, the selectivity to allyl alcohol was enhanced, and this effect was partially irreversible, since a reduction with flowing $\mathrm{H}_{2}$ at 133 mbar for $5 \mathrm{~min}$. after air treatment did not lead to a complete loss

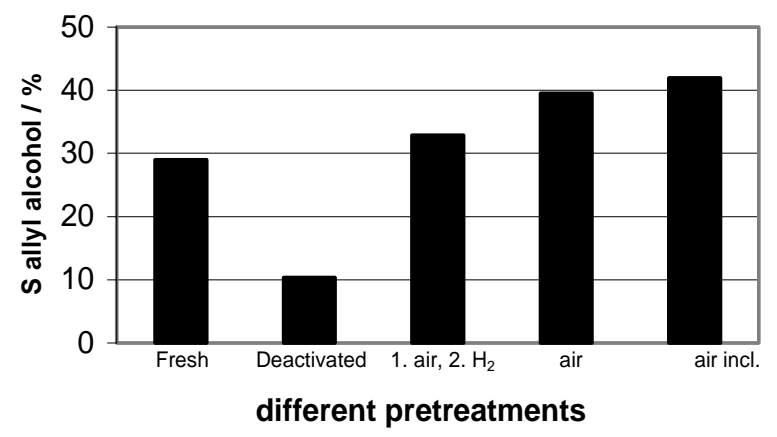

Figure 6: Selectivity to allyl alcohol obtained over $\mathrm{Ag} / \mathrm{ZnO}$ at 800 mbar reaction pressure $\left(\mathrm{H}_{2}: \mathrm{AC} 20: 1\right)$ at $250{ }^{\circ} \mathrm{C}$ after various pretreatment steps (fresh catalyst after preparation; deactivated sample; after air $\left(\& \mathrm{H}_{2}\right)$ treatment; and with 4 mbar air included in the reaction mixture). Experiments were carried out in a static circulation system (i.e. in batch mode). 
of the gained allyl alcohol selectivity, and the enhanced activity remained stable. The highest selectivity to allyl alcohol (42\%) was observed, when a small amount of air (4 mbar) was included into the reaction mixture. The performance of $\mathrm{Ag} / \mathrm{SiO}_{2}$ catalysts was also enhanced. ${ }^{45}$

Similarly enhanced activity and selectivity to allyl alcohol has also been observed in high pressure experiments, where oxygen pretreated $\mathrm{Ag} / \mathrm{SiO}_{2}$ catalysts $\left(250{ }^{\circ} \mathrm{C}\right.$, 1 bar) have been used in acrolein hydrogenation at 10 bar in a continuous gas flow reaction system. ${ }^{45}$ In order to clarify the origin of this behaviour, TEM and XPS experiments have been performed on silver samples in different pretreatment or reaction stages. Transmission electron microscopy indicated that although the oxygen pretreatment at $250{ }^{\circ} \mathrm{C}$ at 1 bar induced re-dispersion of silver particles, the observed catalytic effect however was not related to such a transformation, as after hydrogenation at high pressure the silver mean particle size was independent of the kind of pretreatment applied $^{45}$. On the other hand, X-ray photoelectron spectra carried out using controlled sample transfer from the preparation chamber to the measurement chamber of the XPS without contact to ambient air suggest that oxygen dissolved in silver creates electropositive sites $\left(\mathrm{Ag}^{\delta+}\right)$ on the surface acting as active sites for the hydrogenation. The results in Fig. 7, where the modified Auger parameter $\alpha^{\prime}{ }^{46}$ of differently pre-treated $\mathrm{Ag} / \mathrm{SiO}_{2}$ is shown together with some reference silver materials indicate that oxidation leads to a decrease in the Auger parameter, hence Ag shifts from a "more metallic" to a "more oxidized" state. The catalyst reduced after oxidation did not reach the state of the metal reference. The silver $3 \mathrm{~d}$ core level could be fitted with one state, suggesting that any surface oxide or adsorbed oxygen species ${ }^{47,48,49}$ were destroyed, respectively removed, during hydrogen treatment. In this regard, experiments using $\mathrm{Ag}_{2} \mathrm{O}$ as catalyst also indicated that the oxide is not the active species. ${ }^{45}$ As opposed to any oxidelike species, dissolved or subsurface oxygen is the most compatible with the observations, in agreement with literature data. ${ }^{47,50}$ Furthermore, extended storage of the catalyst sample in air at RT induces similar effects as the treatment in oxygen. ${ }^{45}$ This can be explained by a slow dissolution of oxygen, which occurs already at room temperature. ${ }^{47,50,51}$

XRD measurements after oxidation treatment (not shown) indicated that the bulk silver structure of the $\mathrm{Ag} / \mathrm{SiO}_{2}$ remains metallic even after 1 bar air treatment at $250{ }^{\circ} \mathrm{C}$ for $30 \mathrm{~min}$., suggesting that the effect caused by the oxygen treatment is a superficial one and is probably caused by subsurface oxygen. It is well known that restructuring of silver due to oxygen pre-treatment can occur, creating (111) facets and (110) terminating steps on bulk silver materials. ${ }^{52}$ However, extended smooth surfaces seem to be disadvantageous for allyl alcohol formation as indicated by the better performance of small particles, and, moreover, it is questionable that such oxygen induced faceting remains stable in high-pressure (i.e. 20 bar) hydrogenation conditions. Therefore, we believe that the positive effect of oxygen (air) treatment is connected to the formation of subsurface oxygen species.

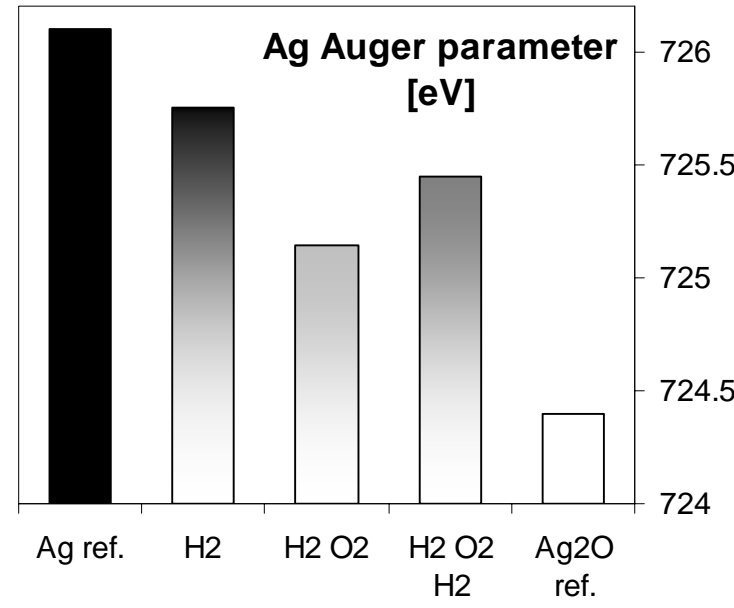

Figure 7: Auger parameter of $\mathrm{Ag} / \mathrm{SiO}_{2}$ after different pretreatments according to XPS analysis. For references Ag foil, unsupported silver nanoparticles, and $\mathrm{Ag}_{2} \mathrm{O}$ were used.

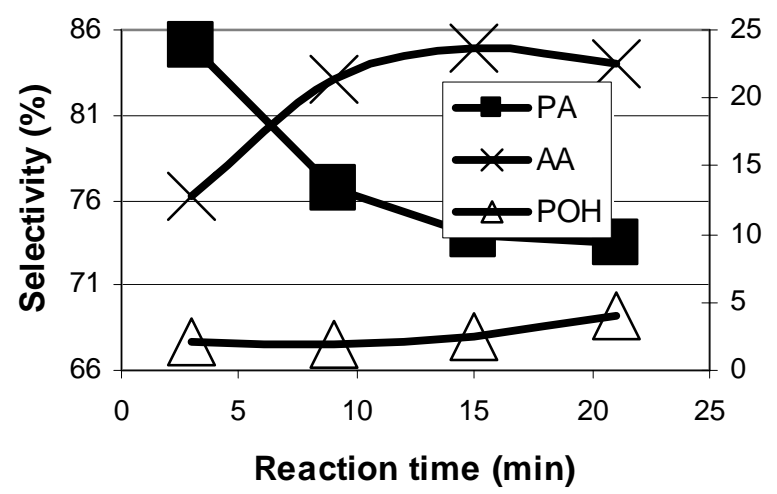

Figure 8: Selectivity to hydrogenation products as a function of reaction time obtained over $7.5 \% \mathrm{Ag} / \mathrm{SiO}_{2}$ at 800 mbar reaction pressure $\left(\mathrm{H}_{2}: \mathrm{AC} 20: 1\right)$ at $250{ }^{\circ} \mathrm{C}$ in a batch experiment.

When a $\mathrm{Ag} / \mathrm{SiO}_{2}$ catalyst is reduced at $325{ }^{\circ} \mathrm{C}$ in 1 bar of hydrogen (without further oxygen treatment), the selectivity to allyl alcohol changes significantly during the first few minutes of reaction. This is displayed in Fig. 8 where the selectivities to allyl alcohol, propanal and $n$ propanol in acrolein hydrogenation are displayed for the first $21 \mathrm{~min}$ of reaction in a batch circulation experiment at 800 mbar. A strong increase in selectivity to allyl alcohol can be seen during the first few minutes. When the same experiment is performed at 266 mbar, the effect is slightly more pronounced. A similar induction of selectivity has been found in gas phase hydrogenation of unsaturated aldehydes over PtSn catalysts. ${ }^{53,54}$ Considering that exposure to the feed (induction period), similar to an oxygen treatment, leads to an enhanced selectivity to allyl alcohol, it may be concluded that silver is oxidised by acrolein to a small extent. Indeed, during catalytic experiments in a continuous flow reactor, even at low conversion always a small amount of $\mathrm{C}_{2}$ and $\mathrm{C}_{3}$ hydrocarbons (not distinguishable by our GC) has been observed in the product stream, Selectivity to 


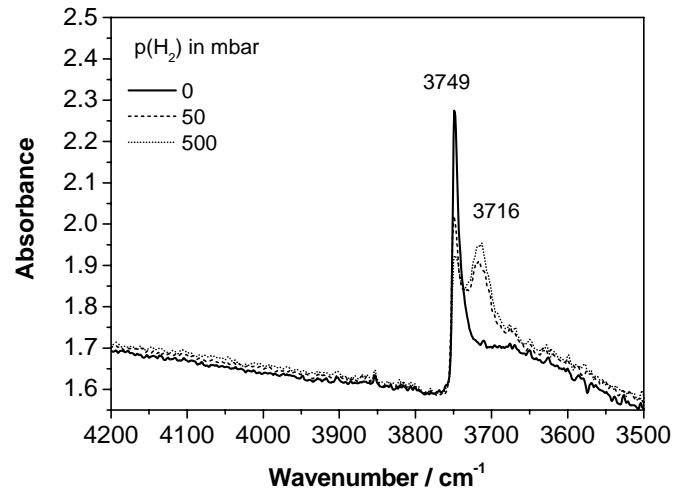

Figure 9: IR spectra of $\mathrm{H}_{2}$ adsorption at liquid nitrogen temperature on $\mathrm{Ag} / \mathrm{SiO}_{2}-\mathrm{P}$, activated at $450^{\circ} \mathrm{C}$ in vacuo.

$\mathrm{C}_{2}, \mathrm{C}_{3}$ ca. $1 \%$. This means that a small amount of oxygen is retained by the catalyst. Additionally, we recently observed with in situ EXAFS that acrolein is indeed able to oxidize indium in AgIn catalysts to some extent in the presence of hydrogen, albeit at higher pressure $(5$ bar $) .{ }^{38}$ This indicates that in principle it is possible to oxidise a catalyst surface by a mixed hydrogen acrolein atmosphere, at least to a low extent.

\section{Activation of hydrogen}

In order to get more insight into the activation of hydrogen on silver, we studied the interaction of hydrogen with silver catalysts using various methods, including temporal analysis of products (TAP), calorimetry ${ }^{16}$ and transmission IR spectroscopy.

Adsorption of $\mathrm{H}_{2}$ on $\mathrm{SiO}_{2}$ and $\mathrm{Ag} / \mathrm{SiO}_{2}$ was studied at liquid nitrogen temperature, following literature reports that $\mathrm{H}_{2}$ can be physisorbed on $\mathrm{Ag}$ at low temperature. ${ }^{25}$ The powders were pressed into self-supporting wafers and activated at $450^{\circ} \mathrm{C}$ in vacuum; spectra were recorded with a PerkinElmer S 2000 FTIR spectrometer. For all samples, a shift of the Si-OH vibrations from $3749 \mathrm{~cm}^{-1}$ to $3716 \mathrm{~cm}^{-1}$ indicated interaction of $\mathrm{H}_{2}$ with the Si-OH groups (Fig. 9); a comparable effect was observed for $\mathrm{D}_{2}$. The free hydrogen molecule does not have any IR active vibrations, but for $\mathrm{H}_{2}$ polarized through adsorption, e.g. on $\mathrm{OH}$ groups of zeolites, ${ }^{55}$ zirconia $^{56}$ or sulfated zirconia, ${ }^{57}$ bands have been detected. However, bands of adsorbed $\mathrm{H}_{2}$, which would be expected $50-60 \mathrm{~cm}^{-1}$ below the gas phase frequency of $4161 \mathrm{~cm}^{-1},{ }^{55}$ could not be detected for $\mathrm{SiO}_{2}$ or $\mathrm{Ag} / \mathrm{SiO}_{2}$. For the adsorption of $\mathrm{H}_{2}$ on the acidic sites of zeolites, Sigl et al. described a highly asymmetric side-on type complex with one $\mathrm{H}$ interacting with a neighboring lattice oxygen; ${ }^{55}$ additionally, the configuration $\mathrm{Si}-\mathrm{OH}-\mathrm{Al}$ naturally produces an asymmetric environment. It is suspected that the complex formed by the silanol groups is possibly very symmetric; also the side-on molecular adsorption of $\mathrm{H}_{2}$ or $\mathrm{D}_{2}$ on a flat Ag surface will not generate an adsorbate with IR ac
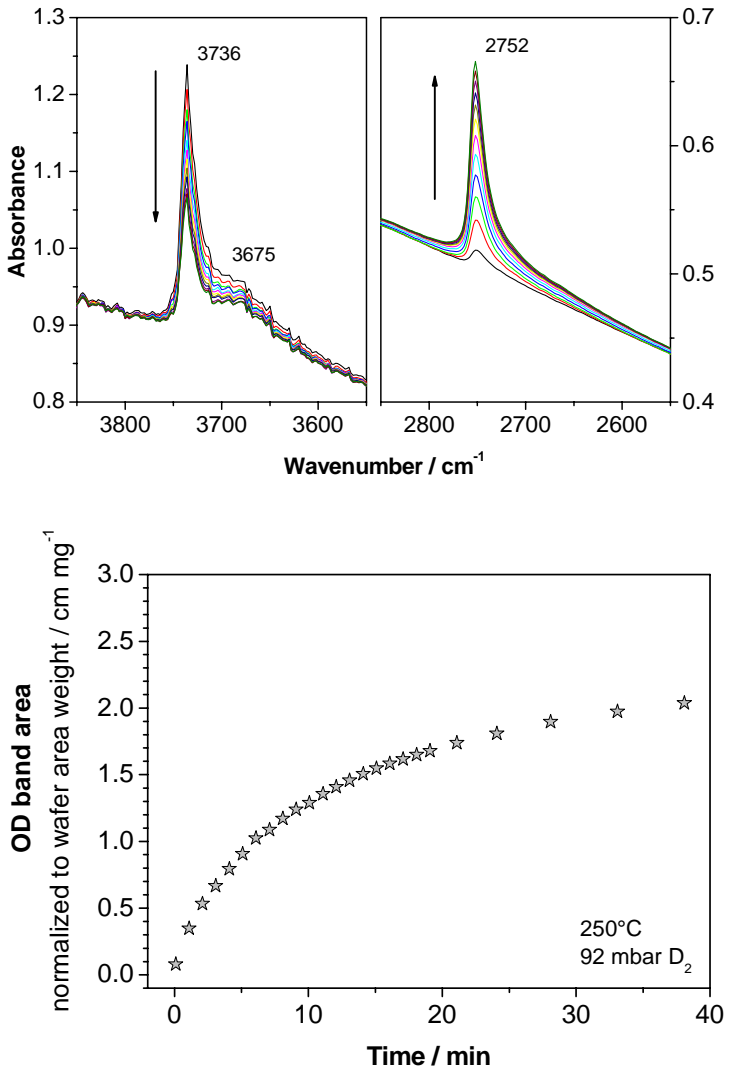

Figure 10: $\mathrm{HD}$ exchange of $\mathrm{Si}-\mathrm{OH}$ groups of $\mathrm{Ag} / \mathrm{SiO}_{2}-\mathrm{IW}$ at $250^{\circ} \mathrm{C}$ and 92 mbar $\mathrm{D}_{2}$.

a) IR spectra with reaction time; b) area of OD band vs. reaction time.

tive vibrations. The results thus do not allow any conclusions regarding $\mathrm{H}_{2}$ adsorption on $\mathrm{Ag}$ catalysts.

While exposing $\mathrm{SiO}_{2}$ or $\mathrm{Ag} / \mathrm{SiO}_{2}$ to $\mathrm{D}_{2}$ at room temperature, however, $\mathrm{Si}-\mathrm{OD}$ groups were formed. The isotopic exchange of $\mathrm{OH}$ groups of silica to $\mathrm{OD}$ groups and the reverse reaction require the cleavage of $\mathrm{D}_{2}$ or $\mathrm{H}_{2}$ molecules, hence this reaction can be considered a model reaction for one of the key steps of hydrogenation, namely the hydrogen activation. The kinetics of the exchange reaction were monitored by transmission IR spectroscopy using self-supporting wafers and a quartz cell. The samples were activated in $\mathrm{H}_{2}$ flow at $325^{\circ} \mathrm{C}$; after evacuation $\mathrm{D}_{2}$ was admitted at the desired reaction temperature. The evolution of the $\mathrm{OH}$ and OD bands $\left(2752 \mathrm{~cm}^{-1}\right)$ in such a batch experiment is shown in Fig. 10a. In general, the area of the appearing OD bands increased linearly in the beginning but then asymptotically approached a final value (Fig. 10b). The fraction of exchangeable $\mathrm{OH}$ groups was between 60 and $70 \%$ for both $\mathrm{SiO}_{2}$ and $\mathrm{Ag} / \mathrm{SiO}_{2}$. Predominantly, the isolated $\mathrm{OH}$ groups absorbing at $3736 \mathrm{~cm}^{-1}$ exchanged (Fig. 10a), confirming assignment of the broad band at lower frequency $\left(\approx 3675 \mathrm{~cm}^{-1}\right)$ to internal $\mathrm{OH}$ groups. ${ }^{58}$ The method of initial rates was used and the slope of the curve in the first minutes was analyzed. The exchange rate increased with increasing temperature and was higher when $\mathrm{Ag}$ was present in the sample. There was no indication for 
two reaction rates in the presence of silver, such as would be expected if the fraction of the $\mathrm{OH}$ groups in the proximity of silver particles exchanged more rapidly than those on the pure support. At high temperatures, mass transfer limitations - either in the wafer or gas exchange within the cell - became obvious, and the initial area increase was not linear (Fig. 10b). Nevertheless, from a sufficient number of measurements at suitable temperatures it will be possible to determine the activation energy for the exchange reaction and thus for the important step of hydrogen activation.

Results from recent TAP experiments confirm the formation of $\mathrm{HD}$, after subsequent pulses of $\mathrm{H}_{2}+\mathrm{D}_{2}$ over an $\mathrm{Ag} / \mathrm{SiO}_{2}$ catalyst at temperatures above $300{ }^{\circ} \mathrm{C}$, whereas the $\mathrm{SiO}_{2}$ alone is inert to this exchange reaction. ${ }^{16}$ The latter is seemingly in contradiction to IR measurements, where H-D-exchange has been observed over the support material, however, the exposure in the TAP experiment is only seconds as opposed to hours in the IR experiments and the $\mathrm{H}_{2}$ partial pressure in the TAP reactor is very low $(\approx 0.1$ mbar). Also, HD exchange for silica has been reported before. ${ }^{59,60}$

Therefore different and independent experiments (TAP and IR) prove that $\mathrm{D}_{2}\left(\mathrm{H}_{2}\right)$ dissociation, one of the key steps in the concerned reaction, is facilitated in presence of supported silver particles. In addition, DSC experiments using $\mathrm{H}_{2}$ pulses showed increasing heat evolution with rising temperature starting from $100{ }^{\circ} \mathrm{C}$ (Fig. 11), indicating an increasing amount of adsorbed hydrogen on $\mathrm{Ag} / \mathrm{SiO}_{2}{ }^{16}$ The dissociation of hydrogen over silver is an activated process, since higher temperatures are necessary for this process (starting from $100{ }^{\circ} \mathrm{C}$, however, depending on the method and the conditions used). The evolved heat is very small compared to that observed for other hydrogenation catalysts like $\mathrm{Pt} / \mathrm{SiO}_{2}$, which is most likely due to both, a lower coverage and a smaller differential heat of adsorption on Ag. In this regard, silver differs from other transition metals like $\mathrm{Pt}$ and $\mathrm{Pd}$, where $\mathrm{H}$ dissociation is non-activated due to the partly vacant valence d-band. ${ }^{61}$ Confirmation for the weak interaction comes from the endothermic signal following the exothermic peak in Fig. 11, suggesting that hydrogen desorbs readily from the catalyst surface as the pulse passes through. ${ }^{16}$

Similar to the catalytic study, calorimetric experiments of hydrogen adsorption have been performed with oxygen pretreated catalysts, however, up to now only on a preliminary basis. These experiments indicate that hydrogen adsorption is indeed enhanced by an oxygen pretreatment of the catalyst. Since, as discussed above, surface oxides or adsorbed oxygen are not stable under hydrogenation conditions, it is likely that subsurface oxygen strengthens the interaction of silver with hydrogen. Consistently, recent theoretical results of $\mathrm{Xu}$ et al. obtained with DFT indicate that hydrogen dissociation is facilitated by subsurface oxygen in $\operatorname{Ag}(111)$ due to the up-shift of the d-band centre. $^{62}$

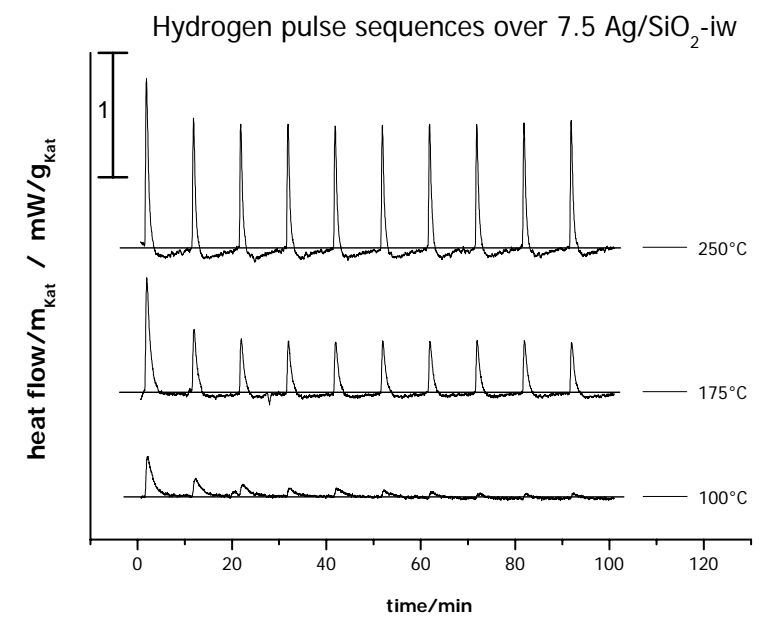

Figure 11: Calorimetric response when dosing hydrogen pulses onto $\mathrm{Ag} / \mathrm{SiO}_{2}$ catalysts at different temperatures

\section{Discussion}

Our investigations revealed that the hydrogenation of acrolein over silver catalysts depends on a complex interplay between pressure, catalyst structure and degree of reduction. The support material, support-metal interface or further additives also seem to be important. Defect sites and subsurface oxygen have been identified as important features regarding activity and selectivity:

\section{a) Activity/hydrogen activation}

As pointed out above, it is somewhat surprising that silver is able to act as a hydrogenation catalyst at all. To do so, it has to activate and dissociate hydrogen. Hydrogen dissociation has clearly been demonstrated by TAP, calorimetry and IR spectroscopic experiments for $\mathrm{Ag} / \mathrm{SiO}_{2}$ catalysts. Since no H-D-exchange has been observed in TAP experiment for electrolytic silver, it may be hypothesized that hydrogen activation occurs at special sites at the interface between support and metal. However, TAP experiments also failed to detect the otherwise proven HD exchange on pure silica, and Boudart and coworkers ${ }^{36} \mathrm{dem}$ onstrated HD exchange on polycrystalline silver, further it is possible to hydrogenate acrolein using unsupported Agnano. Hence, given the right temperature, pressure, and silver structure, $\mathrm{H}_{2}$ can be activated not only at the silver-support interface.

Pre-treatment of the catalysts in oxygen results in an enhanced hydrogen activation, as well as in higher hydrogenation activity. One might conclude that the rate of acrolein hydrogenation is controlled by the hydrogen activation step, but this seems to be inconsistent with the observed structure-insensitivity. Oxygen pre-treatment leads to oxygen species (e.g. subsurface) that produce slightly positively charged silver sites, which indeed have been detected by our XPS measurements. These electrondeficient sites facilitate hydrogen activation, in good 
agreement with DFT calculations, ${ }^{37,62}$ but the dissociated hydrogen atoms are still weakly bound and desorb quickly.

From the literature, it is known that reduction even at $500{ }^{\circ} \mathrm{C}$ does not lead to a complete reduction of silver. ${ }^{63}$ Even at $800{ }^{\circ} \mathrm{C}$, enough oxygen remains dissolved to form water with $\mathrm{H}_{2}$, leading to blister formation in the $\mathrm{Ag} .{ }^{64} \mathrm{The}$ highest reduction temperature used in our studies was 325 ${ }^{\circ} \mathrm{C}$. It is likely that after this treatment some oxygen from the original preparation still remains in the Ag, especially in subsurface locations, even if no extra oxygen pretreatment has been performed. This indeed has been shown by our XPS experiments, where even for the fresh, reduced catalyst a slight shift in the Auger parameter has been detected. The fact that the activity in acrolein hydrogenation is enhanced due to an oxygen treatment is likely explained by a higher number of sites for hydrogen activation. These sites also exist in the freshly prepared, reduced catalyst, however, in a lower amount. A small amount of such sites must be present on unsupported polycrystalline $\mathrm{Ag}$, but they are obviously much more abundant on supported silver.

\section{b) Selectivity}

The results in section 2 demonstrate that the formation of allyl alcohol is related to active sites most abundant on Ag nanoparticles. The smaller the nanoparticles, the higher the amount of allyl alcohol formed, whereas on materials with larger particles or on bulk silver, propionaldehyde formation is preferred. This indicates that lowcoordinated surface sites are responsible for $\mathrm{AyOH}$ formation. Indeed, it has been shown by Itoh and co-workers ${ }^{65}$ that at low temperatures, the carbonyl group of acrolein is co-ordinated to electropositive sites like edges and kinks when adsorbed on silver films, which could lead to an activation and subsequent hydrogenation. Additionally, in our in situ XAS experiments at the C K-edge a flat lying, propionaldehyde-like species was observed at low pressure over single crystal surface. Thus, it is reasonable to assume that propionaldehyde formation is connected to extended surfaces, whereas allyl alcohol formation occurs on edges and kinks. On the other hand, Lim et al. have shown with DFT calculations, that on both low- $\operatorname{Ag}(221)$ and $\mathrm{Ag}(110)$ and high- $\operatorname{Ag}(111)$-coordination sites only weak interaction with acrolein occurs with no significant activation of any bond, making it unlikely that these pure silver surfaces are active for acrolein hydrogenation. ${ }^{66}$ In section 3, we have shown that oxygen introduced by pre-treatment, probably situated in subsurface positions, has a strong influence on selectivity. It has been shown that the amount of oxygen incorporated into silver depends on the size of the nanoparticles. ${ }^{67}$ Therefore, under reaction conditions silver surfaces with incorporated subsurface or bulk oxygen exist, changing the catalytic properties of silver in the desired way. This model is further supported by the induction of selectivity to allyl alcohol at the beginning of a catalytic experiment, and by the appearance of $\mathrm{C}_{2} / \mathrm{C}_{3}$ alkanes in the product feed, which we have interpreted in terms of an "oxidation" of the silver surface by acrolein. This effect may also depend on the particle size, since it should be related to special surface sites able to decompose acrolein. Moreover, evaluation of different supports and of indium as an additive reveals a positive effect of reducible oxides on the desired carbonyl hydrogenation. Low coordination, subsurface oxygen, and interaction with a reducible component all lead to positively charged Ag surface sites; hence either phenomenon can account for the observed increase of the selectivity to allyl alcohol. Neighboring oxygen (partly reduced oxide or subsurface $\mathrm{O}$ ) may render low-coordinated sites even more electropositive, enhancing their effectiveness.

To describe acrolein hydrogenation on a molecular level, based on the importance of the above-discussed proximity of oxygen, the following considerations have to be taken into account. On an Ag single crystal, a flat-lying propionaldehyde-like surface intermediate was identified at relatively low reaction pressure (7.5 mbar), i.e. under conditions where PA is the only hydrogenation product. We assume that the initial adsorption of acrolein occurs also parallel to the silver surface. Above a certain threshold pressure (i.e. at a certain acrolein coverage), allyl alcohol formation sets in and increases with increasing reaction pressure. The pressure barrier exists also for small supported nanoparticles that possess an intrinsic selectivity for hydrogenating the carbonyl function. The threshold pressure for allyl alcohol formation is most likely not related to $\mathrm{H}_{2}$ activation for two reasons; namely hydrogenation occurs already at lower pressures and the selectivity curve

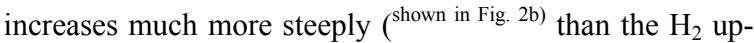
take curve for $\mathrm{Ag}$, which is proportional to $\mathrm{p}^{1 / 2}{ }^{35}$ The fact that the reaction order for $\mathrm{AyOH}$ formation decreases from 0.84 to 0.54 when increasing the pressure from 5 to $15 \mathrm{bar}$ indicates that acrolein coverage should play an important role in $\mathrm{AyOH}$ formation. The coverage changes become less significant with increasing pressure, as evidenced by the marginal increase in selectivity beyond 10 bar (Fig. 2b).

Loffreda et al. reported a coverage-dependent acrolein adsorption geometry on $\operatorname{Pt}(111)$, and the main difference at high coverage is that the carbonyl group is decoordinated from the surface. ${ }^{68} \mathrm{~A}$ corresponding change of adsorption state can be imagined on silver, but is has to be clarified which end of the molecule will remain attached to the surface. The presence of oxygen in surface-near regions generates $\mathrm{Ag}^{\delta+}$ and results in a polar surface, which should favor the adsorption of the more polar carbonyl function over the $\mathrm{C}=\mathrm{C}$ double bond. It has been shown that the binding of a $\mathrm{C}=\mathrm{C}$ double bond may be enhanced as well on kinks and edges ${ }^{69}$ and that subsurface oxygen in silver may strengthen the binding of adsorbed ethylene, too, ${ }^{62,70}$ but the effect on the carbonyl function should be much more pronounced. In agreement with the results of Itoh et al., ${ }^{65}$ we therefore assume that at low pressure acrolein is fully coordinated to the surface. At high coverage however, the adsorption geometry changes, and the molecules detach partially and the double bond oriented parallel to the sur- 
face will be hydrogenated. This scenario is further supported by the better selectivity for carbonyl group hydrogenation that is observed for molecules with bulky substituents at the $\mathrm{C}=\mathrm{C}$ double bond, because in this case, coordination of the $\mathrm{C}=\mathrm{C}$ double bond to the surface is restricted. Most likely electropositive sites serve as anchoring points for the carbonyl function, but it can be imagined that pure, flat $\mathrm{Ag}$ surface attract the $\mathrm{C}=\mathrm{C}$ double bond, which would explain the limit in selectivity shown in Fig. 2b. The maximum selectivity would then be determined by the ratio of electropositive to regular Ag sites.

\section{Concluding remarks}

The gas phase hydrogenation of acrolein over silver as model reaction was found to be strongly pressure dependent in the range 1 mbar to $10 \mathrm{bar}$, with the additional complication that structure, morphology and reduction degree of $\mathrm{Ag}$ particles and thus the nature of the Ag sites depends on the pre-treatment and reaction conditions and the support.

From these facts, some consequences result for investigations regarding this catalytic reaction. A threshold pressure of about 100 mbar for the desired pathway of allyl alcohol formation has been identified, making it currently impossible to apply surface science methods to the operating catalyst. Furthermore, morphology changes of Ag were more dramatic in vacuum than under typical reaction conditions, making it difficult to transfer conclusions e.g. from TPD data. Hydrogen activation was found to be activated, making low temperature physisorption experiments irrelevant, and the interaction at temperatures sufficiently high for activation was weak, again making it impracticable to study hydrogen adsorption and activation by surface science techniques. The catalytic performance improved with the abundance of defect sites, and consistently information on the nature of intermediates of the unwanted reaction pathway was obtained from adsorption on ideal silver surfaces. Hence, there is a "materials gap" but model materials deliver valuable reference data. The catalyst chemistry changed under reaction conditions; oxygen was incorpo-

\section{References and Notes}

[1] P. Claus, Top. Catal., 1998, 5, 51.

[2] V. Ponec, Appl. Catal. A, 1997, 149, 27.

[3] P. Gallezot and D. Richard, Catal. Rev. Sci. Eng., 1998, 40, 81.

[4] F. Delbecq and P. Sautet, J. Catal., 1995, 152, 217-236.

[5] F. Delbecq and P. Sautet, J. Catal., 2002, 211, 398.

[6] P. Beccat, J.C. Bertolini, Y. Gauthier, J. Massardier and P. Ruiz, J. Catal., 1990, 126, 451-456.

[7] C.M. Pradier, T. Birchem, Y. Berthier and G. Cordier, Catal. Lett., 1994, 29, 371-378.

[8] D. Loffreda, F. Delbecq, F. Vigne and P. Sautet, J. Am. Chem. Soc., 2006, 128, 1316.

[9] B.C. Khanra, Y. Jugnet and J.C. Bertolini, J. Molecular Cat. A: Chemical, 2004, 208, 167-174. rated due to the chemical potential of oxygen arising from the presence of acrolein. The particle structure cannot be considered as static property; sintering or redispersion of the silver can occur depending on the support, leading to structural features very different from those found in precatalytic or ex situ measurements. As both however opposite effects were observed as a function of reaction pressure, the effect of pressure and material discussed above are sometimes inseparably interconnected. With the material's properties being dynamic, structure-activity relationships can only be established through in situ experiments under typical reaction conditions.

Although, at present, it is not possible for us to present a detailed microkinetic analysis, the following current picture on the acrolein hydrogenation over Ag catalysts has evolved: The activity depends on the number of electrondeficient sites that are available for $\mathrm{H}_{2}$ activation. Such sites can be generated through low coordination of $\mathrm{Ag}$ atoms or proximity of incorporated oxygen, support material or a combination thereof. High hydrogen pressures are necessary to achieve significant hydrogen surface coverage due to weak interaction. The selectivity depends on the adsorption geometry, which depends on the structural features of the nanoparticles (low coordination site, polarized $\mathrm{Ag}$ atoms), and the reaction pressure. Hence for both, activity and selectivity, defect sites, subsurface oxygen and oxide patches play a paramount role in acrolein hydrogenation over silver.

\section{Acknowledgements}

Funding was provided by DFG within the frame of the priority program 1091 "Bridging the gap between real and ideal systems in heterogeneous catalysts", grants CL168/1, JE267/3 and.SCHL332/3. The BESSY staff is gratefully acknowledged for the support during the in situ C K-edge NEXAFS measurements. The authors would like to thank B. Freitag, G. Weinberg and D.S. Su for providing the electron microscopy images and U. Wild for acquiring XP spectra.
[10] M.A. Vannice and B. Sen, J. Catal., 1989, 115, 65-78.

[11] M.A. Vannice, Top. Catal., 1997, 4, 241-248.

[12] P. Claus, S. Schimpf, R. Schödel, P.Kraak, W. Mörke and D. Hönicke, Appl. Catal. A: General, 1997, 165, 429-441.

[13] T.B.L.W. Marinelli, S. Nabuurs and V. Ponec, J. Catal., 1995, 151, 431-438.

[14] Y. Nagase, Ibaraki Daigaku Kogakubu Kenkyo Shuko, 1991, 39, 165-168.

[15] W. Grünert, A. Brückner, H. Hofmeister and P. Claus, J. Phys. Chem. B, 2004, 108, 5709-5717.

[16] M. Bron, E. Kondratenko, A. Trunschke and P. Claus, Z. Phys. Chem., 2004, 218, 405-423.

[17] M. Bron, D. Teschner, A. Knop-Gericke, B. Steinhauer, A. Scheybal, M. Hävecker, D. Wang, R. Födisch, D. Hönicke, 
A. Wootsch, R. Schlögl and P. Claus, J. Catal., 2005, 234, 37-47.

[18] P. Claus, A. Brückner, C. Mohr and H. Hofmeister, J. Am. Chem. Soc., 2000, 122, 11430-11439.

[19] C. Mohr, H. Hofmeister, J. Radnik and P. Claus, J. Am. Chem. Soc., 2003, 125, 1905-1911.

[20] C. Mohr, H. Hofmeister and P. Claus, J. Catal., 2003, 213, 86-94.

[21] P. Claus, Appl. Catal. A: General, 2005, 291, 222-229.

[22] M. Bron, M. Bonifer, C. Volckmar, P. Claus, in preparation.

[23] M. Lucas and P. Claus, Chem.-Ing.-Tech., 2005, 77, 110-114.

[24] M. Lucas and P. Claus, Chem. Eng. Technol., 2005, 28, 867870.

[25] Ph. Avouris, D. Schmeisser and J. E. Demuth, Phys. Rev. Lett., 1982, 48, 199-202.

[26] G. Lee, P. T. Sprunger, M. Okada, D. B. Poker, D. M. Zehner and E. W. Plummer, J. Vac. Sci. Technol. A, 1994, 12, 2119 2123.

[27] X.-L. Zhou, J. M. White and B. E. Koel, Surf. Sci., 1989, 218, 201-210.

[28] A. Eichler, G. Kresse and J. Hafner, Surf. Sci., 1998, 397, 116-136.

[29] A. Montoya, A. Schlunke and B. S. Haynes, J. Phys. Chem. B, 2006, 110. 17145-17154.

[30] A. Eichler, J. Hafner, A. Groß and M. Scheffler, Phys. Rev. B, 1999, 59, 13297-13300.

[31] C. Mijoule and V. Russier, Surf. Sci., 1991, 254, 329-340.

[32] C. Qin and J. L. Whittem, J. Phys. Chem. B, 2005, 109, 8852-8856.

[33] B. Hammer and J. K. Norskov, Surf. Sci., 1995, 343, 211-220 and Erratum: B. Hammer and J. K. Norskov, Surf. Sci., 1996, 359, 306.

[34] G. Lee and E. W. Plummer, Phys. Rev. B, 2000, 62, 16511654.

[35] E. W. R. Steacie and F. M. G. Johnson, Proc. Roy. Soc. A, 1928, 117, 662-679.

[36] R. J. Mikovksy, M. Boudart and H. S. Taylor, J. Am. Chem. Soc., 1954, 76, 3814-3819.

[37] A. B. Mohammad, K. H. Lim, I. V. Yudanov, K. M. Neyman and N. Rösch, Phys. Chem. Chem. Phys. in press.

[38] F. Haass, M. Bron, H. Fuess and P. Claus, Appl. Catal. A, 2007, 318, 9-16.

[39] M. Bron, D. Teschner, A. Knop-Gericke, A. Scheybal, B. Steinhauer, M. Hävecker, R. Födisch, D. Hönicke, R. Schlögl and P. Claus, Catal. Commun., 2005, 6, 371-374.

[40] G. Y. Popova, A. A. Davydov, T. V. Andrushkevich and I. I. Zakha, Kinet. Katal., 1995, 36, 136

[41] J. E. Bailie, C. H. Rochester and G. J. Hutchings, J. Chem. Soc. Faraday Trans., 1997, 93, 4389.

[42] R. van Hardeveld and F. Hartog, Surf. Sci., 1969, 15, 189 230.

[43] J. M. Montejano-Carrizales, F. Aguilera-Granja and J. L. Morán-Lopez, Nanostructured Materials, 1997, 8, 269-287.

[44] P. Claus and H. Hofmeister, J. Phys. Chem. B, 1999, 103, 2766-2775.
[45] M. Bron, D. Teschner, A. Knop-Gericke, C. Volckmar, B. Steinhauer, A. Wootsch, R. Schlögl and P. Claus, in preparation.

[46] C. D. Wagner, Faraday Discuss. Chem. Soc., 1975, 160, 291.

[47] X. Bao, M. Muhler, Th. Schedel-Niedrig and R. Schlögl, Phys. Rev. B, 1996, 54, 2249.

[48] V. I. Bukhtiyarov, V. V. Kaichev and I. P. Prosvirin, J. Chem. Phys., 1999, 111, 2169-2175.

[49] V. I. Bukhtiyarov, M. Hävecker, V. V. Kaichev, A. KnopGericke, R. W. Mayer and R. Schlögl, Phys. Rev. B, 2003, 67, 235422.

[50] C. Rehren, G. Isaac, R. Schlögl and G. Ertl, Catal. Lett., 1991, 11, 253-266.

[51] C. Rehren, M. Muhler, X. Bao, R. Schlögl and G. Ertl, Z. Phys. Chem., 1991, 174, 11-52.

[52] D. Herein, A. Nagy, H. Schubert, G. Weinberg, E. Kitzelmann and R. Schlögl, Z. Phys. Chem.-Int., 1996, 197, 67-96. and A. Nagy PhD Thesis Technical University of Eindhoven, 1998

[53] T. B. L. Marinelli and V. Ponec, J. Catal., 1995, 156, 51-59.

[54] J. L. Margitfalvi, A. Tompos, I. Kolosova and J. Valyon, J. Catal., 1998, 174, 246-249.

[55] M. Sigl, S. Ernst, J. Weitkamp and H. Knözinger, Catal. Lett. 1997, 45, 27-33.

[56] J. Kondo, K. Domen, K.-i. Maruya and T. Onishi, Chem. Phys. Lett., 1992, 188, 443-445.

[57] B. S. Klose, F. C. Jentoft, R. Schlögl, I. R. Subbotina and V. B. Kazansky, Langmuir, 2005, 21, 10564-10572.

[58] H.-P. Boehm and H. Knözinger, in Catalysis Science and Technology, eds J. R. Anderson and M. Boudart, Springer Verlag, Berlin, 1983, Vol. 4, pp.39-207.

[59] W. K. Hall, H. P. Leftin, F. J. Cheselske, and E. R. O'Reilly, J. Catal., 1963, 2, 506-517.

[60] D. Martin and D. Duprez, J. Phys. Chem. B, 1997, 101, 44284436.

[61] C.G. Bond, Catalysis by metals, Academic Press, London and New York, 1962, pp 65-69.

[62] Y. Xu, J. Greeley and M. Mavrikakis, J. Am. Chem. Soc., 2005, 127, 12823-12827.

[63] Z. Qu, S. Zhou, W. Wu, C. Li and X. Bao, Catal. Lett., 2005, 101, 21-26.

[64] R. L. Klueh and W. W. Mullins, Trans. Metal. Soc. AIME, 1968, 242, 237-244.

[65] S. Fujii, N. Osaka, M. Aktia and K. Itoh, J. Phys. Chem., 1995, 99, 6994-7001.

[66] K. H. Lim, Z.-X. Chen, K. M. Neyman and N. Rösch, Chem. Phys. Lett., 2006, 420, 60-64.

[67] D.C. Lim, I. Lopez-Salido and X.D. Kim, Surf. Sci., 2005, 598, 96-103.

[68] D. Loffreda, Y. Jugnet, F. Delbecq, J. C. Bertolini and P. Sautet, J. Phys. Chem. B, 2004, 108, 9085-9093.

[69] A. Kokalj, A. Dal Corso, S. de Gironcoli and S. Baroni, J. Phys. Chem. B, 2002, 106, 9839-9846.

[70] A. Kokalj, A. Dal Corso, S. de Gironcoli and S. Baroni, Surf. Sci., 203, 532-535, 191-197. 